\title{
Antigenic Targets in Tienilic Acid Hepatitis \\ Both Cytochrome P450 2C11 and 2C11-Tienilic Acid Adducts Are Transported to the Plasma Membrane of Rat Hepatocytes and Recognized by Human Sera
}

\author{
Marie-Anne Robin, ${ }^{\star}$ Michel Maratrat, ${ }^{\ddagger}$ Marie Le Roy, ${ }^{\star}$ François-Pierre Le Breton, ${ }^{*}$ Eric Bonierbale, ${ }^{\S}$ Patrick Dansette, ${ }^{\S}$ \\ François Ballet, ${ }^{\ddagger}$ Daniel Mansuy, ${ }^{\S}$ and Dominique Pessayre* \\ *Institut National de la Santé et de la Recherche Medicale U-24 and Centre de Recherche de Physiopathologie Hépatique (Association \\ Claude Bernard), Hôpital Beaujon, 92118 Clichy; ${ }^{\ddagger}$ Département Sécurité du Médicament, Rhône-Poulenc Rorer, 94140 Alfortville; and \\ ${ }^{\S}$ Unité de Recherche Associée 400, Centre National de la Recherche Scientifique, 75005 Paris, France
}

\begin{abstract}
Patients with tienilic acid hepatitis exhibit autoantibodies that recognize unalkylated cytochrome P450 2C9 in humans but recognize $2 \mathrm{C} 11$ in rats. Our aim was to determine whether the immune reaction is also directed against neoantigens. Rats were treated with tienilic acid and hepatocytes were isolated. Immunoprecipitation, immunoblotting, and flow cytometry experiments were performed with an anti-tienilic acid or an anti-cytochrome P450 2C11 antibody. Cytochrome P450 2C11 was the main microsomal or plasma membrane protein that was alkylated by tienilic acid. Inhibitors of vesicular transport decreased flow cytometric recognition of both unalkylated and tienilic acid-alkylated cytochrome P450 2C11 on the plasma membrane of cultured hepatocytes. Tienilic acid hepatitis sera that were preadsorbed on microsomes from untreated rats (to remove autoantibodies), poorly recognized untreated hepatocytes in flow cytometry experiments, but better recognized tienilic acid-treated hepatocytes. This recognition was decreased by adsorption with tienilic acid or by preexposure to the anti-tienilic acid or the anti-cytochrome P450 2C11 antibody. We conclude that cytochrome P450 2C11 is alkylated by tienilic acid and follows a vesicular route to the plasma membrane. Tienilic acid hepatitis sera contain antibodies against this tienilic acid adduct, in addition to the previously described anticytochrome P450 autoantibodies. (J. Clin. Invest. 1996. 98: 1471-1480.) Key words: cell traffic - vesicular transport • microtubules $\bullet$ neoantigen $\bullet$ immunoallergic hepatitis
\end{abstract}

\section{Introduction}

The uricosuric diuretic, tienilic acid (TA), was withdrawn from clinical use in the United States after more than 500 cases of hepatic injury and 25 fatalities were reported to the manufacturer (1). The prompt recurrence of the disease in the patients

Address correspondence to D. Pessayre, M.D., INSERM U-24, Hôpital Beaujon, 92118, Clichy, France.

Received for publication 5 March 1996 and accepted in revised form 12 July 1996.

J. Clin. Invest.

(C) The American Society for Clinical Investigation, Inc.

0021-9738/96/09/1471/10 \$2.00

Volume 98, Number 6, September 1996, 1471-1480 that were rechallenged suggested an immune mechanism (1). TA is transformed by cytochrome $\mathrm{P}^{4} 50^{1}$ (P450) $2 \mathrm{C} 9$ into a reactive metabolite, presumably the thiophene sulfoxide (2-4). When yeast microsomes expressing P450 2C9 were incubated with TA, nicotinamide adenine dinucleotide (NADPH), and glutathione (to trap the reactive metabolite that migrates away from $\mathrm{P} 450$ 2C9), the only protein that was alkylated by TA metabolites was P450 2C9 $(3,4)$. In the sera of patients with TA hepatitis, there are type 2 anti-liver kidney microsome (anti$\mathrm{LKM}_{2}$ ) autoantibodies that react with liver and kidney sections from untreated rats (5). These autoantibodies recognize P450 2C9 in humans (2-6), but recognize P450 2C11 in rats (a major isoform in adult male liver that exhibits $85 \%$ sequence identity with P450 2C9) (7).

$\mathrm{P} 450$ s are cotranslationally inserted into the endoplasmic reticulum (ER) membrane, where they remain anchored by a noncleaved signal-anchor sequence $(8,9)$. A cytosolic domain may serve as an ER retention signal (10). There is an extensive flow of vesicles that migrate along microtubules, from the ER to the plasma membrane (PM), via the Golgi apparatus, and transport endoluminal or membrane-bound proteins to the $\mathrm{PM}$, with a mean transit time of 15 to $30 \mathrm{~min}$ (11). P4502B in part follows this vesicular route to reach the PM of rat hepatocytes (12). Likewise, several other P450s are present on the $\mathrm{PM}$ of rat and human hepatocytes, and are oriented, at least in part, on the outer surface of this membrane $(13,14)$. These PM P450s may serve as antigenic targets for the anti-P450 2D6, $2 \mathrm{C} 9$, or $1 \mathrm{~A} 2$ autoantibodies $(13,14)$ that develop, respectively, in patients with type- 2 idiopathic autoimmune hepatitis, TA hepatitis, or dihydralazine hepatitis (15).

Dihydralazine is transformed by rat and human P450 1A2 into reactive radicals that covalently bind to rat and human P450 1A2 proteins (16). Subjects with dihydralazine hepatitis exhibit anti-liver microsome autoantibodies that recognize human and rat liver P450 1A2 (17). Therefore, both with TA and with dihydralazine, metabolic activation by a particular P450 and covalent binding to this P450 lead to the appearance of autoantibodies that recognize the unalkylated $\mathrm{P} 450$ protein (15). However, in several other instances of drug-induced hepatitis, there are antibodies that recognize the alkylated parts of hepatic proteins (18). Thus, reactive metabolites apparently cause an immune attack that is directed against the

1. Abbreviations used in this paper: anti-LKM $\mathrm{LM}_{2}$, type 2 anti-liver kidney microsome; anti-TA antibody, anti-tienilic acid-protein adducts antibody; ER, endoplasmic reticulum; P450, cytochrome P450; PM, plasma membrane. 
"unmodified Self" in the cases of TA and dihydralazine, but against the "modified Self" in the cases of several other drugs (18-22). Whether this dichotomy is absolute or only partial, however, remains to be demonstrated. Indeed, most anti$\mathrm{LKM}_{2}$ sera showed higher cytotoxicity than control sera in an antibody-dependent cell-mediated cytotoxicity assay that was performed with hepatocytes from rabbits treated first with $\beta$-naphthoflavone and then TA (23). However, the nature of the suspected neoantigens was not studied (23).

In the present study, we used immunoprecipitation, immunoblot and flow cytometry techniques to demonstrate $(a)$ that TA administration to rats causes the formation of TA-alkylated $\mathrm{P} 4502 \mathrm{C} 11$ in the ER, $(b)$ that this alkylated P450 follows a microtubule-dependent vesicular route from the ER to the $\mathrm{PM}$, and (c) that anti-LKM $\mathrm{KM}_{2}$ sera recognize TA-alkylated P450 $2 \mathrm{C} 11$ on the PM of TA-treated rats.

\section{Methods}

Materials. Tienilic acid was a gift of Anphar-Rolland Laboratories (Chilly-Mazarin, France). Cobaltous chloride and paraformaldehyde were from Merck, (Darmstadt, Germany). Sodium pentobarbital was from Centravet, (Plancoët, France). Hydrocortisone was from RousselUclaf, (Paris, France). Streptomycin and penicillin were from GIBCO BRL Life Technols., Inc., (Gaithersburg, MD). Brefeldin A, caffeine, colchicine, cycloheximide, vinblastine, and acetaminophen were purchased from Sigma Chemical Co., (St. Louis, MO). Piperonyl butoxide was from Koch-Light Laboratories, (Coinbrook Bucks, England).

Animals and treatments. Male or female Sprague-Dawley CDCrl: $\mathrm{CD}(\mathrm{SD}) \mathrm{BR}$ rats were purchased from Charles River Laboratories (Cléon, France). The rats were fed ad libitum and were used when they weighed $\sim 160-200 \mathrm{~g}$. The rats received humane care (24), and the study was approved by our Institutional Review Board.

The rats were either untreated or were treated with a single dose of TA $(100 \mathrm{mg} / \mathrm{kg}$ : body weight $)$ administered intraperitoneally in 4 $\mathrm{mM}$ Tris buffer, $30 \mathrm{~min}$ to $36 \mathrm{~h}$ before death. Some of these rats also received piperonyl butoxide ( $400 \mathrm{mg} / \mathrm{kg}$ i.p.) or colchicine $(2.5 \mathrm{mg} /$ $\mathrm{kg}$ i.p.) administered either before or after TA administration. Other animals were pretreated with cobaltous chloride $(35 \mathrm{mg} / \mathrm{kg}$ s.c. twice daily for $3 \mathrm{~d}$ ). TA was administered $17 \mathrm{~h}$ after the last dose of $\mathrm{CoCl}_{2}$.

Isolation of hepatocytes. Nonfasted rats were anesthetized with pentobarbital, and hepatocytes were isolated by a two-step in situ perfusion, as described (12). Briefly, the liver was perfused with Hepes buffer, followed by single-pass perfusion with $0.025 \%$ collagenase A (Boehringer Mannheim, Mannheim, Germany). The liver was dissociated in Leibovitz L-15 medium (GIBCO BRL) containing $0.2 \%$ bovine serum albumin (Sigma). Hepatocytes were centrifuged twice with Hepes buffer and once with William's E medium (Eurobio, Les Ulis, France). Cell viability, estimated by trypan blue exclusion, averaged $90 \%$.

Preparation of microsomes and PM. Isolated hepatocytes were washed with PBS, scraped in PBS, centrifuged, resuspended in $0.1 \mathrm{M}$ phosphate buffer, $\mathrm{pH} 7.4$, sonicated on ice for $45 \mathrm{~s}$ with a $80 \mathrm{~W}$ sonicator, and used to prepare microsomes, as described (25).

PM-coated beads were prepared from isolated hepatocytes as described (12). The technique is based on the electrostatic attachment of hepatocytes to polyacrylamide beads (Biogel P-2, fine; Bio-Rad Laboratories, Richmond, CA) coated with polyethyleneimine (12-14). Polyglutamate is then added to cover the bare regions remaining between attached hepatocytes, thus preventing the binding of non-plasma membrane fractions during homogenization. After disruption of hepatocytes by vortex mixing, sedimentation, and several washings, PM-coated beads are obtained $(13,14)$. A 50\% (vol/vol) suspension of beads is then prepared in $10 \mathrm{mM}$ Tris- $\mathrm{HCl}$ buffer, $\mathrm{pH}$ 7.4. The PM proteins are then obtained by solubilization in $3 \%$ sodium dodecyl sulfate and concentrated if necessary $(<1 \mathrm{mg} / \mathrm{ml})$. Microsomal contamination of this PM fraction is less than $1 \%$, as judged from the specific activities of several marker enzymes in the PM and microsomal fraction, respectively $(13,14)$.

Cell culture. Hepatocytes $\left(8 \times 10^{6}\right.$ cells $)$ were seeded in $100 \mathrm{~mm}$ Petri dishes containing William's E medium with $0.1 \mathrm{mg} / \mathrm{ml}$ insulin (Sigma), $100 \mathrm{IU} / \mathrm{ml}$ penicillin, $0.1 \mathrm{mg} / \mathrm{ml}$ streptomycin, $0.07 \mathrm{mM}$ hydrocortisone, and 10\% fetal calf serum (Dominique Dutscher, Brumath, France) (12). Hepatocytes were maintained at $37^{\circ} \mathrm{C}$ in a humidified incubator under $5 \% \mathrm{CO}_{2}$ in air for $3 \mathrm{~h}$ (12).

After cell attachment, the medium was removed and replaced by a medium that differed by the absence of fetal calf serum and the presence or not of various agents. Caffeine, cycloheximide, and vinblastine were prepared in William's E medium, and used at final concentrations of $10 \mathrm{mM}, 10 \mu \mathrm{M}$, and $11 \mu \mathrm{M}$, respectively (12). Brefeldin A and piperonyl butoxide were dissolved in methanol, and added at a final concentration of $18 \mu \mathrm{M}$ and $0.5 \mathrm{mM}$, respectively; the final concentration of methanol in the culture medium was $0.2 \%$. Hepatocytes treated with $0.2 \%$ methanol served as controls for these experiments; methanol had no effect on the PM expression of unalkylated or TAalkylated P450 2C11.

Human sera. Serum samples containing anti-LKM 2 autoantibodies were obtained from patients suffering from tienilic acid-induced hepatitis. The presence of anti-LKM $\mathrm{L}_{2}$ autoantibodies in these sera had been detected and titrated by immunofluorescence as described (5). Control sera were obtained from blood donors who had never taken tienilic acid.

These anti-LKM 2 or control sera were used either without preadsorption or after they had been preadsorbed on rat liver microsomes from untreated rats $(2 \mathrm{ml}$ of a 1 -in-10 dilution were preadsorbed on 4 $\mathrm{mg}$ microsomal proteins before use). Some sera were first reacted with TA $(1 \mathrm{mM})$ or acetaminophen (as a control) before being used.

Purified P450 2C11, anti-P450 2C11, and anti-TA-protein adducts antibodies. Preparation and characterization of purified cytochrome P450 2C11 has been described (26). Polyclonal antibodies against P450 2C11 were raised in rabbits (13).

To prepare anti-TA-protein adducts antibodies (subsequently abbreviated as anti-TA antibodies), bovine serum albumin-TA adducts were prepared as described $(3,15)$. In these adducts, the TA molecule is bound through its thiophene moiety, thus mimicking the binding of the TA reactive metabolite $(3,15)$. Rabbits were immunized with these bovine serum albumin-TA adducts, and the immune sera were collected $(3,15)$.

The anti-TA antibody was used without preadsorption for immunoblots. For flow cytometric analysis, however, the anti-TA antibody was first preadsorbed on untreated rat hepatocytes. $1 \mathrm{ml}$ of the antiTA serum diluted 1:100 was adsorbed on $50 \times 10^{6}$ cells and recovered by centrifugation. This preadsorption totally suppressed the nonspecific labeling of untreated hepatocytes that was otherwise observed (possibly as a consequence of the presence of anti-albumin antibodies in the unadsorbed anti-TA antibodies).

Immunoblots. PM proteins $(20 \mu \mathrm{g})$ and microsomal proteins $(10$ $\mu \mathrm{g})$ were subjected to electrophoresis on sodium dodecyl sulfate- $9 \%$ polyacrylamide gels and transferred to nitrocellulose sheets (12). The nitrocellulose sheets were incubated with the anti-P450 2C11 or the anti-TA antibody (both diluted 1:100 in PBS containing 10\% newborn calf serum), and then to peroxidase-conjugated swine immunoglobulins raised against rabbit immunoglobulins $\mathrm{G}$ and diluted 1:1000 (Dakopatts, Copenhagen, Denmark). Other blots were first exposed to an anti-LKM ${ }_{2}$ serum (diluted 1:50) for $45 \mathrm{~min}$ at room temperature, and then to peroxidase-conjugated rabbit immunoglobulins raised against human immunoglobulins A, G, M, kappa, and lambda, and diluted 1:1000 in PBS (Dakopatts).

Peroxidase staining was revealed with 3,3'-diaminobenzidine and $\mathrm{H}_{2} \mathrm{O}_{2}$, in the presence of $0.015 \% \mathrm{CoCl}_{2}$ and $0.015 \% \mathrm{NiCl}_{2}$ (25). Quantification of the protein bands was performed on an LKB Ultroscan XL enhanced laser densitometer (Pharmacia Fine Chemicals, Uppsala, Sweden) (25). In preliminary experiments, the linearity of densi- 
tometry measurements was verified by depositing various amounts of microsomal $(2.5,5$, and $10 \mu \mathrm{g})$ or PM proteins $(5,10$, and $20 \mu \mathrm{g})$.

Immunoprecipitation. Microsomes from rats killed $4 \mathrm{~h}$ after TA administration were resuspended in 1\% Nonidet P40 (BDH Lab Chemicals Ltd., Poole, England), $150 \mathrm{mM} \mathrm{NaCl}, 1 \mathrm{mM}$ EDTA, $20 \mathrm{mM}$ Tris/ $\mathrm{HCl}$ lysis buffer, $\mathrm{pH} 8$ (27). After protein measurement, microsomes were diluted to a microsomal protein concentration of $0.2 \mathrm{mg} / \mathrm{ml}$, in $0.1 \%$ bovine serum albumin, $1 \%$ Nonidet $\mathrm{P} 40,150 \mathrm{mM} \mathrm{NaCl}, 1 \mathrm{mM}$ EDTA, $10 \mathrm{mM}$ Tris/HCl lysis buffer, $\mathrm{pH} 8$ (27). $1 \mathrm{ml}$ was incubated with the anti-TA antibody $(20 \mu \mathrm{l})$ for $1 \mathrm{~h}$ at room temperature. $10 \mathrm{mg}$ of protein A-Sepharose CL-4B (Pharmacia, Freiburg, Germany) were added to the mixture and rotated end-over-end overnight at $4^{\circ} \mathrm{C}$. Beads were pelleted by centrifugation and washed six times, exactly as described (27). The immunocomplexes were then resuspended in $100 \mu \mathrm{l}$ of $5 \%$ sodium dodecyl sulfate, $20 \%$ glycerol, $10 \%$ mercaptoethanol, $0.025 \%$ pyronin $\mathrm{Y}$, and $1.5 \mathrm{M}$ Tris/HCl buffer, $\mathrm{pH}$ 6.8 , containing $1 \mathrm{mM}$ TA. Immunoprecipitated proteins were eluted from protein A-Sepharose by heating at $95^{\circ} \mathrm{C}$ for $3 \mathrm{~min}$, and $2 \mu \mathrm{l}$ were subjected to sodium dodecyl sulfate- $9 \%$ polyacrylamide gel electrophoresis as described above. After transfer, the nitrocellulose sheet was cut and revealed with either Coomassie blue (to stain proteins) or the anti-2C11 antibody as described above.

Flow cytometry. Isolated or cultured hepatocytes were analyzed by flow cytometry (12). When cultured hepatocytes were used, the cells were detached with $3 \mathrm{mM}$ EDTA, and resuspended in Hanks'
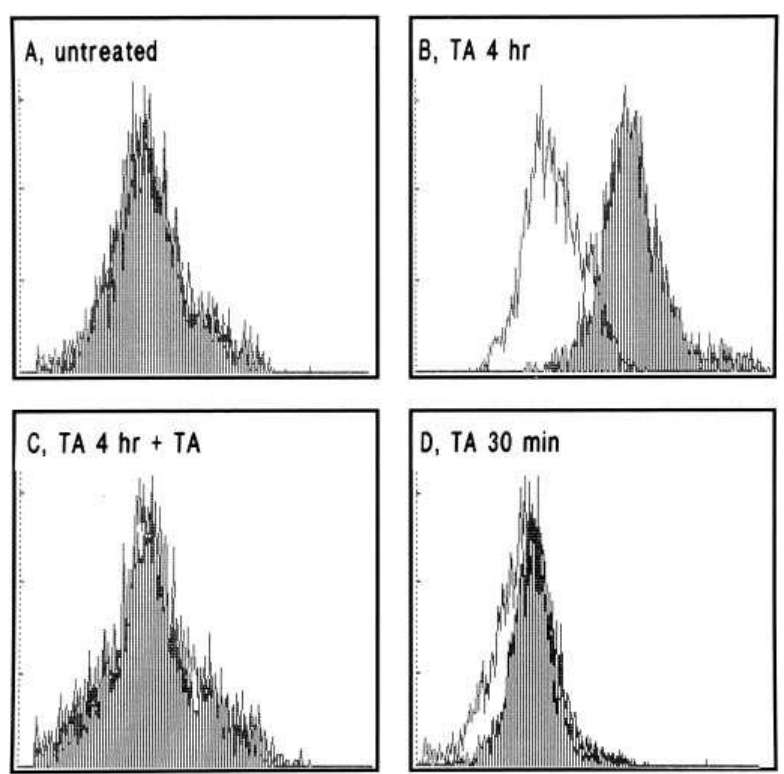

Figure 1. Flow cytometry analysis of TA-alkylated proteins on the $\mathrm{PM}$ of isolated hepatocytes exposed either to nonimmune rabbit serum or to the anti-TA antibody, and then to an FITC-labeled antirabbit immunoglobulin. (A) Untreated rat hepatocytes; $(B)$ Rats killed $4 \mathrm{~h}$ after TA administration $(100 \mathrm{mg} / \mathrm{kg}) ;(C)$ Same hepatocytes but exposed to an anti-TA antibody that had been first reacted with TA (1 mM); (D) Rats killed 30 min after TA administration. The histograms show the number of cells (arithmetic scale) with a given fluorescence (log scale). The white histograms correspond to hepatocytes incubated with the nonimmune rabbit serum (unspecific fluorescence). The black histograms correspond to hepatocytes incubated with the anti-TA antibody. The difference in the relative linear fluorescence intensity derived from the logarithmic mean channel number for the black histogram and the white histogram represents an index of the specific labeling of PM proteins. This difference (mean \pm SEM for four experiments, each in duplicate) was: $(A) 0.0 \pm 0.2$ fluorescence units; $(B) 6.0 \pm 0.5$; $(C) 0.3 \pm 0.1 *$; $(D) 0.7 \pm 0.1 * . * P<0.01$ as compared to $(B)$. balanced salt solution (12). Hepatocytes $(500,000)$ were exposed to nonimmune rabbit serum (diluted 1:100) as a control, or to the antiP450 2C11 antibody (diluted 1:100), or the anti-TA antibody (diluted 1:100) that had been preadsorbed on untreated hepatocytes as described above. After $30 \mathrm{~min}$ of incubation at $4^{\circ} \mathrm{C}$, hepatocytes were washed, and incubated at $4^{\circ} \mathrm{C}$ for $30 \mathrm{~min}$ with fluorescein isothiocyanate (FITC)-labeled anti-rabbit immunoglobulins (Institut Pasteur Production, Marnes-la-Coquette, France) diluted 1:50 (vol/vol) in PBS.

Other hepatocytes were incubated with control human sera or anti-LKM ${ }_{2}$ sera (both diluted 1:10 in Hanks' balanced salt solution) for $1 \mathrm{~h}$ at $4^{\circ} \mathrm{C}$, and then exposed to FITC-labeled antibodies raised against human immunoglobulins $\mathrm{G}, \mathrm{A}$, and $\mathrm{M}(\mathrm{H}+\mathrm{L})$ (Institut Pasteur Production) for $30 \mathrm{~min}$ at $4^{\circ} \mathrm{C}$. In some experiments, either the anti-P450 2C11 or the anti-TA antibody was added before the human serum. These antibodies, which are both raised in rabbits, are not recognized by the FITC-anti-human immunoglobulin. Therefore PM fluorescence only detects the human antibodies.

Propidium iodide $(10 \mu \mathrm{g} / \mathrm{ml})$ was added for $15 \mathrm{~min}$ to label dead cells (12). Hepatocytes were fixed with $2 \%$ paraformaldehyde for $20 \mathrm{~min}$ (12). Cells were analyzed on an ATC 3000 (ODAM, Wissembourg, France) flow cytometer equipped with an Innova 90-6 argon ion laser (Coherent, Palo Alto, CA) tuned to $488 \mathrm{~nm}$ and delivering $400 \mathrm{~mW}$ output power, exactly as previously reported (12). The sheath medium was $0.9 \% \mathrm{NaCl}$, and the flow rate was about 1,000 events/s. 5,000 cells were analyzed for each sample. All signals were recorded in a linear mode, except for the green fluorescence of FITC which was recorded in a log mode (12). Gates were placed both on the scattergram to exclude debris and aggregates, and on the cytogram of forward angle light scatter versus propidium iodide fluorescence to exclude dead cells (12).

The logarithmic mean channel number of each histogram was converted into relative linear fluorescence intensity (12). The linear fluorescence intensity for the histogram obtained with the control serum (unspecific fluorescence) was subtracted from that for the histogram obtained with the anti-TA, anti-P450 2C11, or anti-LKM ${ }_{2}$ antibodies. The difference, an index of the specific labeling of the plasma membrane (12), was then compared, in control and in variously treated hepatocytes, by analysis of variance and Dunnett's t-test.

Confocal scanning microscopy. Cells were exposed to the antiTA antibody and the FITC-labeled anti-rabbit immunoglobulin as described above. Cells were placed on a slide in Glycergel (Dakopatts), and analyzed on an ACAS 570 (Meridian Instruments, Inc., Okemos, MI) as described (12).

\section{Results}

Unless otherwise indicated, experiments were performed on male rats.

Flow cytometric assessment of the presence of TA-containing structures on hepatocytes from TA-treated rats. The anti-TA antibody did not recognize the PM of untreated rat hepatocytes (Fig. $1 A$ ), but produced marked fluorescence with hepatocytes that were isolated $4 \mathrm{~h}$ after TA administration (Fig. $1 B$ ). This is shown by the rightward shift (i.e., higher fluorescence) of the black histogram (exposure to the anti-TA antibody) compared to the white histogram (exposure to non-immune rabbit serum) (Fig. $1 \mathrm{~B}$ ). PM labeling was confirmed by confocal scanning microscopy (Fig. 2).

Addition of TA $(1 \mathrm{mM})$ to the anti-TA antibody prior to use, suppressed this PM fluorescence (Fig. $1 C$ ), showing that the anti-TA antibody specifically recognized TA-containing structure(s).

Plasma and hepatic TA levels were much higher $30 \mathrm{~min}$ than $4 \mathrm{~h}$ after TA administration (28). If the anti-TA antibody had recognized unbound TA on the PM, then this antibody should have recognized the PM at early times after TA admin- 


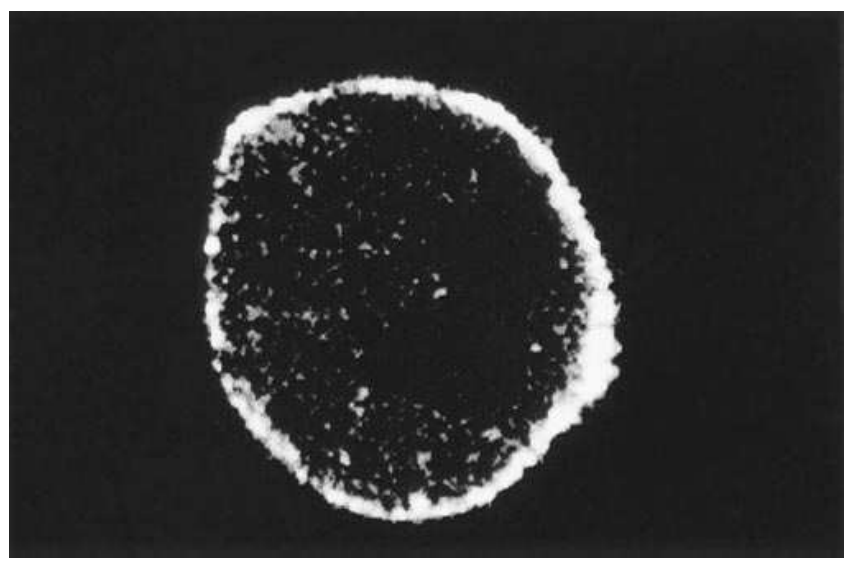

Figure 2. Confocal scanning microscopy analysis of the PM localization of TA-alkylated proteins. Isolated hepatocytes were prepared $4 \mathrm{~h}$ after administration of TA $(100 \mathrm{mg} / \mathrm{kg})$. Uncut, nonpermeabilized hepatocytes were exposed to the anti-TA antibody diluted 1:100 and then to an FITC-labeled anti-rabbit immunoglobulin. Hepatocytes were fixed, and analyzed by confocal scanning microscopy. Marked labeling of the PM is observed.

istration. However, the anti-TA antibody did not recognize the PM of hepatocytes prepared 30 min after TA administration (Fig. $1 D$ ). This indicated that the structures that were recognized at later times were TA-protein adducts rather than unbound TA. Probably, most of TA and its non-covalently bound metabolites were removed by the perfusion procedure $(750 \mathrm{ml})$ and the multiple washings during the isolation of hepatocytes.

Demonstration by immunoprecipitation that P450 2 C11 is the main protein alkylated by $T A$. Hepatic microsomes were prepared $4 \mathrm{~h}$ after TA administration, and TA-containing proteins were immunoprecipitated with the anti-TA antibody (Fig. 3). Immunoprecipitated proteins were eluted and analyzed by sodium dodecyl sulfate-polyacrylamide gel electrophoresis. Coomassie blue staining showed a single protein band that comigrated with the band recognized by the anti2C11 antibody (Fig. 3). This indicated that P450 2C11 is the main protein alkylated by TA in the ER.

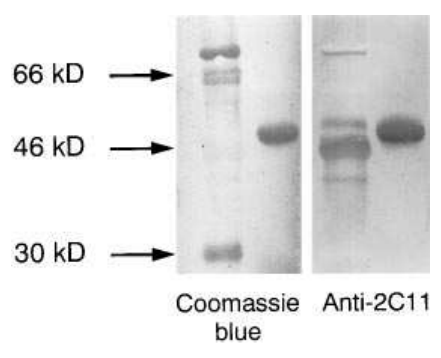

Figure 3. Immunoprecipitation of TA-alkylated P450 2C11 by the anti-TA antibody. Hepatic microsomes were prepared from rats killed $4 \mathrm{~h}$ after TA administration $(100 \mathrm{mg} / \mathrm{kg})$. Microsomal proteins $(0.2 \mathrm{mg})$ were exposed to $20 \mu$ l of the anti-TA antibody and then to protein A-Sepharose beads. After washings, beads were resuspended in a volume of $100 \mu \mathrm{l}$. Immunoprecipitated proteins were eluted by heating and aliquots $(2 \mu \mathrm{l})$ of the supernatant were subjected to sodium dodecyl sulfate- $9 \%$ polyacrylamide gel electrophoresis. The nitrocellulose sheets were cut and exposed either to Coomassie blue (to reveal proteins) or to the anti-2C11 antibody diluted 1:100. Lane 1: $2.5 \mu \mathrm{l}$ of Rainbow colored protein molecular weight markers (Amersham). Lane 2: immunoprecipitated proteins.
Immunoblotting assessment of the effects of various treatments on the expression of TA-alkylated P450 2 C11 in microsomes and PM. Microsomal and PM fractions were prepared from hepatocytes that were isolated $4 \mathrm{~h}$ after TA administration. The anti-TA antibody recognized a main protein band (as well as several very weakly labeled bands) in immunoblots of microsomal and PM proteins (Fig. 4). This main band comigrated with microsomal, PM, or purified P450 2C11 (Fig. 4), confirming that P450 2C11 was the main protein alkylated by TA.

Diverse treatments were performed to modify the formation or transport of TA-alkylated P450 2C11 (Fig. 5). The antiTA antibody did not recognize P450 2C11 (or any other protein) in microsomes or PM from untreated rats (Fig. 5). The 1,3-benzodioxole derivative, piperonyl butoxide, forms an inactive iron-carbene complex with P450 (29). Pretreatment with piperonyl butoxide should decrease metabolic activation of TA and thus TA-alkylated P450 2C11 in hepatocytes from TA-treated rats. Indeed, this pretreatment markedly decreased the band that was recognized by the anti-TA antibody in microsomes and PM (Fig. 5). In contrast, posttreatment with piperonyl butoxide ( $1 \mathrm{~h}$ before killing) had no effect (Fig. 5).

$\mathrm{CoCl}_{2}$ inhibits ferrochelatase and this may have several effects (30). A major, initial effect is to decrease the formation of the $\mathrm{P} 450$ holoenzymes (30). Second, the P450 apoproteins may then undergo enhanced proteolysis (30), and, possibly, may be less transported to the PM. Diminution of the active holoenzyme should markedly decrease the metabolic activation of TA, whereas only the latter effects should decrease P450 2C11 levels in microsomes or PM. These differences may explain why $\mathrm{CoCl}_{2}$ markedly decreased the band recognized by the anti-TA antibody in microsomes and PM, whereas it barely decreased the band recognized by the anti-2C11 antibody in microsomes but still decreased it in the PM (Fig. 5).

Colchicine prevents the polymerization of microtubules (31), thus interrupting the flow of vesicles that migrate along microtubules from the ER to the PM, and the transport of P450 2B from the ER to the PM (12). Due to the relatively long half-life of P450 in the ER and its rapid turnover in the
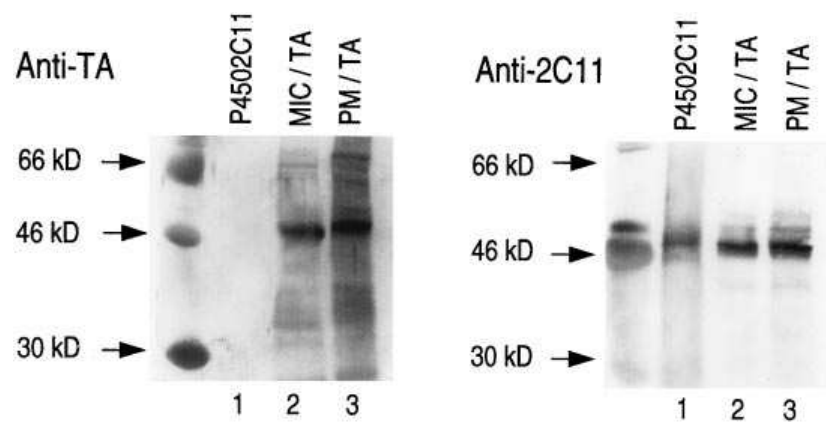

Figure 4. Immunoblots of microsomal and PM proteins of hepatocytes from TA-treated rats. Hepatocytes were isolated $4 \mathrm{~h}$ after TA administration. Microsomal fractions (MIC/TA) and PM fractions (PM/TA) were prepared. Sodium dodecyl sulfate-9\% polyacrylamide gels were loaded with $2.5 \mu \mathrm{l}$ of Rainbow colored protein molecular weight markers (Amersham), 1.5 pmol of the purified P450 2C11 (lane 1), $10 \mu \mathrm{g}$ of microsomal proteins (lane 2) and $20 \mu \mathrm{g}$ of PM proteins (lane 3). After transfer to nitrocellulose, the blots were developed with the anti-TA or the anti-P450 2C11 antibody, each diluted $1: 100$. 

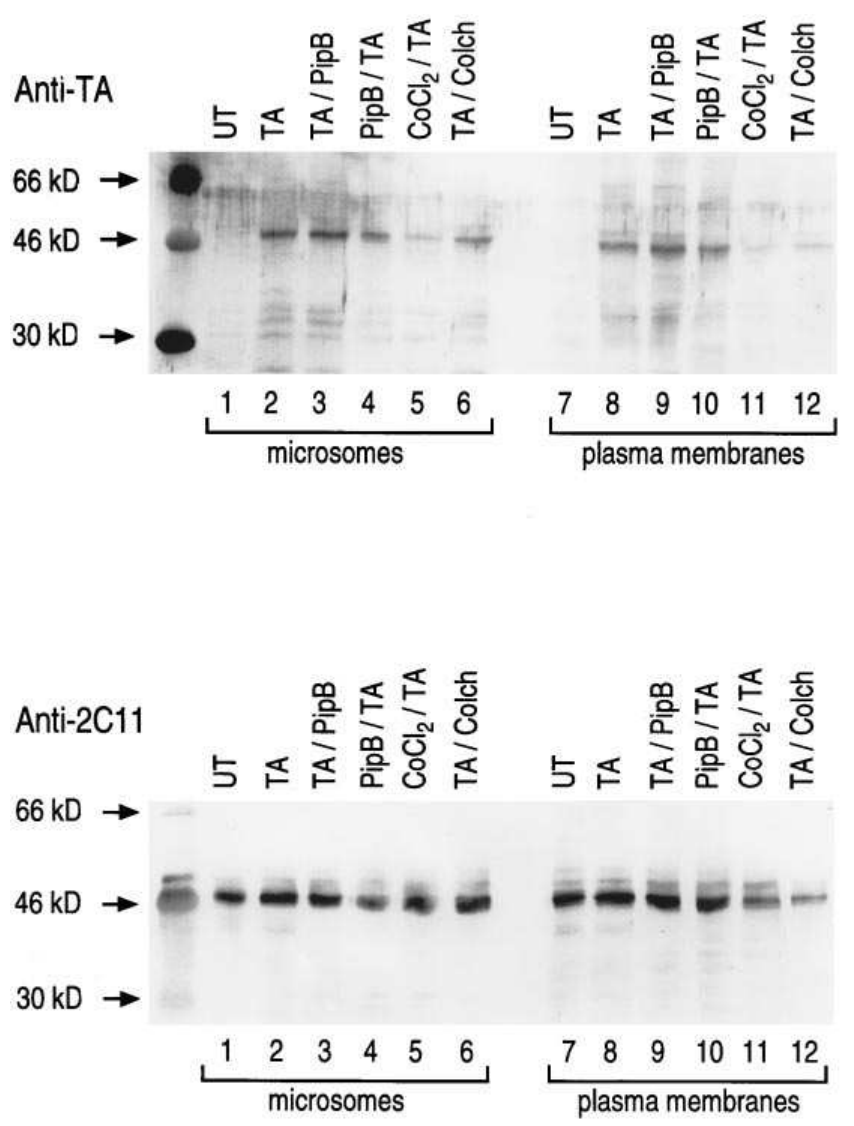

Figure 5. Assessment of the effects of various treatments on the microsomal and PM expression of total and TA-alkylated P450 2C11 by immunoblotting. Hepatocytes were isolated and both microsomes and PM were prepared after various treatments: UT, untreated rats; TA, rats treated with TA $4 \mathrm{~h}$ before killing; TA/PipB, rats that received TA and then piperonyl butoxide, $4 \mathrm{~h}$ and $1 \mathrm{~h}$ before death, respectively; PipB/TA, piperonyl butoxide and then TA, 5 and $4 \mathrm{~h}$ before death; $\mathrm{CoCl}_{2} / \mathrm{TA}$, rats that were pretreated with $\mathrm{CoCl}_{2}$ for $3 \mathrm{~d}$ and then treated with TA $4 \mathrm{~h}$ before death; TA/colch, rats receiving TA and then colchicine, 4 and $3 \mathrm{~h}$ before death, respectively. Sodium dodecyl sulfate- $9 \%$ polyacrylamide gels were loaded with $2.5 \mu$ of Rainbow colored protein molecular weight markers (Amersham), 10 $\mu \mathrm{g}$ of microsomal proteins (lanes 1-6) and $20 \mu \mathrm{g}$ of PM proteins (lanes 7-12). After transfer to nitrocellulose, blots were developed with the anti-TA or the anti-P450 2C11 antibody, each diluted 1:100.

PM (12), colchicine should have little effect on the level of P450 2C11 in the ER but should markedly decrease it in PM. Indeed, pretreatment with colchicine did not modify the P450 band that was recognized by the anti-P450 $2 \mathrm{C} 11$ antibody in microsomes, but markedly decreased it in the PM (Fig. 5). Colchicine slightly decreased the band recognized by the antiTA antibody in microsomes (Fig. 5), suggesting that colchicine may also inhibit the metabolism of TA. Colchicine essentially supressed the band recognized by the anti-TA antibody in the PM (Fig. 5).

Confirmation by flow cytometry of the effects of these treatments on the expression of TA-alkylated P450 2 C11 in the PM. To confirm these results (and validate the flow cytometry technique), the effects of these various treatments were assessed by flow cytometry analysis (Table I). Pretreatment with piperonyl butoxide slightly decreased (by $27 \%$ ) the PM fluores- cence mediated by the anti-P450 2C11 antibody (labeling P450 2C11), but markedly decreased (by $83 \%$ ) the PM fluorescence that was mediated by the anti-TA antibody (labeling TA-alkylated P450 2C11) (Table I). In contrast, posttreatment with piperonyl butoxide ( $1 \mathrm{~h}$ before killing) had no effect (Table I). Pretreatment with $\mathrm{CoCl}_{2}$ decreased $\mathrm{PM}$ labeling with both the anti-P450 2C11 and the anti-TA antibodies (Table I). Pretreatment with colchicine, which decreases $\mathrm{P} 450$ transport to the $\mathrm{PM}$, decreased the PM fluorescence that was mediated by both the anti-P450 2C11 and the anti-TA antibodies (Table I).

Because P450 2C11 is a major isoform of the adult male rat liver, but is not expressed in the adult female liver (26), we also compared male and female hepatocytes. Whereas the anti-TA antibody produced marked PM fluorescence in male rats, it barely recognized the PM of female hepatocytes (Fig. 6).

In vivo time course of the levels of TA-alkylated P450 2 C11 in microsomes and PM. Immunoblots of microsomes and PM, and flow cytometric analysis of the PM, were performed 0, 2, 6, 12, or $36 \mathrm{~h}$ after TA administration (Fig. 7). Whereas the microsomal and PM expression of P450 2C11 (measured with the anti-P450 2C11 antibody) remained stable throughout the experiment, TA-alkylated P450 2C11 (measured with the antiTA antibody) was absent at time 0 in microsomes, increased to reach a plateau from 2 to $6 \mathrm{~h}$ after TA administration and then exhibited a progressive decline (Fig. 7). TA-alkylated P450 $2 \mathrm{C} 11$ exhibited a similar time course in the PM with, however, a slight rightward shift (Fig. 7).

Vesicular transport of both P450 2 C11 and TA-alkylated $P 4502 C 11$ from the ER to the PM. In a previous study, P450 2B was found to have a short half-life in the PM (possibly because of PM reinternalization through endocytosis), and the addition of agents that interrupted its vesicular transport from the ER to the PM markedly decreased its presence in the PM after $2 \mathrm{~h}$ of culture (12). In the present study, hepatocytes were isolated $12 \mathrm{~h}$ after TA administration (to allow for the in vivo

Table I. Flow Cytometry Assessment of the Effects of Various In Vivo Treatments on the PM Expression of TA-alkylated and Unalkylated P450 2C11

\begin{tabular}{lcc}
\hline & \multicolumn{2}{c}{ Specific fluorescence } \\
\cline { 2 - 3 } \multicolumn{1}{c}{ In vivo treatments (time before death) } & \multicolumn{1}{c}{ Anti-TA } & Anti-2C11 \\
\hline & \multicolumn{2}{c}{ (Fluorescence Units) } \\
TA $(4 \mathrm{~h})$ & $6.6 \pm 0.4$ & $8.4 \pm 0.5$ \\
TA $(4 \mathrm{~h})+$ piperonyl butoxide $(1 \mathrm{~h})$ & $7.9 \pm 0.4$ & $7.1 \pm 0.7$ \\
Piperonyl butoxide $(5 \mathrm{~h})+$ TA $(4 \mathrm{~h})$ & $1.1 \pm 0.2^{*}$ & $6.1 \pm 0.2^{*}$ \\
CoCl $_{2}(3 \mathrm{~d})+$ TA $(4 \mathrm{~h})$ & $1.0 \pm 0.4^{*}$ & $0.6 \pm 0.04^{*}$ \\
TA $(4 \mathrm{~h})+$ colchicine $(3 \mathrm{~h})$ & $1.3 \pm 0.3^{*}$ & $0.7 \pm 0.1^{*}$ \\
\end{tabular}

Hepatocytes were isolated after various in vivo treatments, as indicated. Flow cytometry analysis was performed after exposure either to nonimmune rabbit serum or to the anti-TA or anti-P450 2C11 antibody, each diluted 1:100. The logarithmic mean channel number of each histogram was converted into relative linear fluorescence intensity. The linear fluorescence intensity for the histogram obtained with the control serum (unspecific fluorescence) was subtracted from that for the histogram obtained with either the anti-TA or the anti-P450 $2 \mathrm{C} 11$ antibodies. The difference, an index of the specific labeling of the plasma membrane, is set in the Table (means \pm SEM for three experiments, each in triplicate). $* P<0.05$, as compared to TA. 

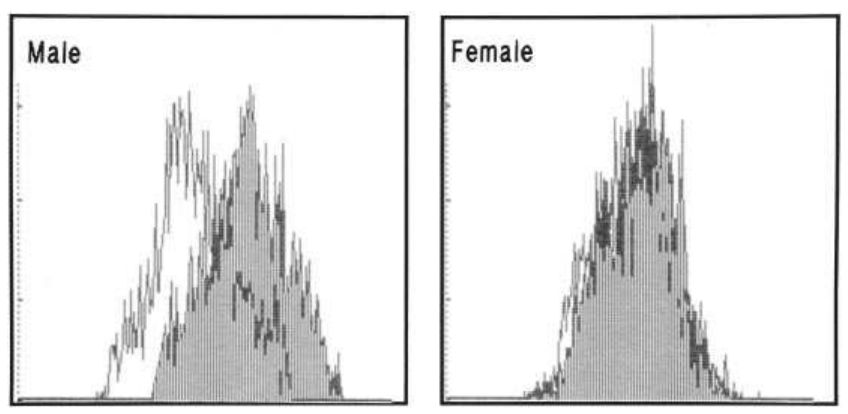

Figure 6. Flow cytometry comparison of the PM expression of TAalkylated P450 2C11 in male and female rats. Hepatocytes were isolated $4 \mathrm{~h}$ after administration of TA. Flow cytometry analysis was performed after exposure either to non-immune rabbit serum (white histograms) or to the anti-TA antibody (black histograms), each diluted 1:100. The difference in the linear fluorescence intensity for the black and white histograms (means \pm SEM for three experiments, each in triplicate) was $6.6 \pm 0.4$ fluorescence units for male rats, but $1.3 \pm 0.3 *$ for female rats ( $* P<0.01$, as compared to male rats).

formation of the P450 2C11-TA metabolite adduct in the ER) and were then cultured for $2 \mathrm{~h}$ (to allow for the in vitro transport of ER P450 to the PM and its turnover in the PM). The PM expression of both P450 2C11 and TA-alkylated P450 2C11 was then studied by flow cytometry (Table II). As indicated above, the perfusion of the liver with collagenase and the several washings to prepare isolated hepatocytes may remove most unbound TA, thus interrupting the in vitro formation of TA-alkylated P450 2C11. Indeed, addition of the P450 inhibitor, piperonyl butoxide to the culture medium barely decreased (not significant) this PM expression (Table II). Never-

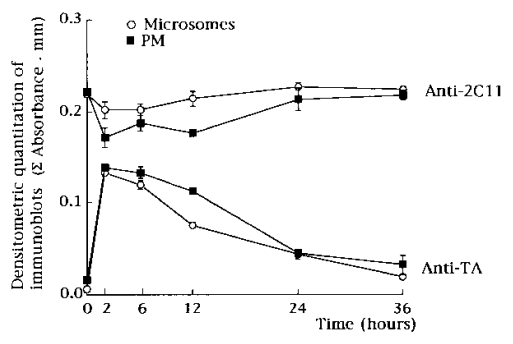

Figure 7. Assessment of the time course of TAalkylated and total $\mathrm{P} 450$ $2 \mathrm{C} 11$ by immunoblotting and flow cytometry. Hepatocytes were prepared at various times after TA administration. Some hepatocytes were used to prepare microsomes and PM.

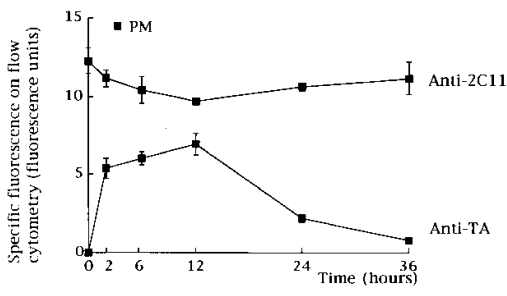
Sodium dodecyl sulfate$9 \%$ polyacrylamide gels were loaded with $10 \mu \mathrm{g}$ of microsomal proteins and $20 \mu \mathrm{g}$ of PM proteins. Nitrocellulose blots were developed with the anti-TA

or the anti-P450 2C11 antibody, each diluted 1:100. The sum area absorbance of the protein peak (means \pm SEM for three to four immunoblots) was quantitated by laser densitometry. Other hepatocytes were exposed either to nonimmune rabbit serum, or to the anti-TA or anti-P450 2C11 antibody, and were studied by flow cytometry. The specific fluorescence (means \pm SEM for three experiments, each in duplicate) was calculated as the difference between the relative linear fluorescence intensity derived from the logarithmic mean channel number with the test serum and that with the nonimmune rabbit serum.
Table II. Flow Cytometry Assessment of the In Vitro Effects of Various Inhibitors of Vesicular Transport on the PM Expression of TA-alkylated and Unalkylated P450 2 C11

\begin{tabular}{llc}
\hline & \multicolumn{2}{c}{ Specific fluorescence } \\
\cline { 2 - 3 } \multicolumn{1}{c}{ In vitro treatments } & Anti-TA & Anti-2C11 \\
\hline & \multicolumn{2}{c}{ (Fluorescence Units) } \\
Control, $37^{\circ} \mathrm{C}$ & $8.2 \pm 0.6$ & $6.8 \pm 0.2$ \\
Piperonyl butoxide $(0.5 \mathrm{mM})$ alone, $37^{\circ} \mathrm{C}$ & $7.2 \pm 0.2$ & $6.5 \pm 0.3$ \\
Cycloheximide $(10 \mu \mathrm{M}) \pm$ Piperonyl, $37^{\circ} \mathrm{C}$ & $2.6 \pm 0.3^{*}$ & $1.3 \pm 0.2^{*}$ \\
Low temperature \pm Piperonyl, $20^{\circ} \mathrm{C}$ & $6.0 \pm 0.4^{*}$ & $4.9 \pm 0.2^{*}$ \\
Caffeine $(10 \mathrm{mM}) \pm$ Piperonyl, $20^{\circ} \mathrm{C}$ & $4.7 \pm 0.5^{*}$ & $2.4 \pm 0.2^{*}$ \\
Brefeldin A $(18 \mu \mathrm{M}) \pm$ Piperonyl, $37^{\circ} \mathrm{C}$ & $4.4 \pm 0.5^{*}$ & $2.2 \pm 0.2^{*}$ \\
Colchicine $(10 \mu \mathrm{M}) \pm$ Piperonyl, $37^{\circ} \mathrm{C}$ & $3.2 \pm 0.5^{*}$ & $3.1 \pm 0.2^{*}$ \\
Vinblastine $(11 \mu \mathrm{M}) \pm$ Piperonyl, $37^{\circ} \mathrm{C}$ & $3.3 \pm 0.4^{*}$ & $2.4 \pm 0.3^{*}$ \\
& & \\
\end{tabular}

Hepatocytes were isolated $12 \mathrm{~h}$ after TA administration and cultured for $2 \mathrm{~h}$ with or without inhibitors of vesicular transport. The latter were added either with piperonyl butoxide, to study the transport of TAalkylated P450 2C11, or alone, to study the transport of P450 2C11. Hepatocytes were exposed to non-immune rabbit serum or to the antiTA or anti-P450 2C11 antibody and analyzed by flow cytometry. The linear fluorescence intensity with the control serum (unspecific fluorescence) was subtracted from that obtained with either the anti-TA or the anti-P450 $2 \mathrm{C} 11$ antibodies. The difference, an index of the specific labeling of the plasma membrane, is set in the Table (means \pm SEM for three experiments, each in triplicate). ${ }^{*} P<0.05$, as compared to the corresponding control (piperonyl butoxide for TA-alkylated P450; control, $37^{\circ} \mathrm{C}$ for $\left.\mathrm{P} 4502 \mathrm{C} 11\right)$.

theless, to further ensure that no P450 alkylation would occur in vitro, all studies on the transport of TA-alkylated P450 2C11 were performed in the presence of piperonyl butoxide (Table II). These experiments therefore studied the in vitro transport of adducts that had been formed in vivo.

Cycloheximide, an inhibitor of protein synthesis, caffeine at $20^{\circ} \mathrm{C}$, which decreases vesicular flow from the ER to the Golgi apparatus (32), brefeldin A, which redistributes Golgi structures back into the ER (33), and colchicine and vinblastine, which both inhibit the assembly of microtubules and the flow of vesicles along microtubules $(31,34)$, all decreased the



Figure 8. Western blot analysis of microsomal and PM fractions from untreated and TAtreated rat hepatocytes after exposure to an anti-LKM $\mathrm{L}_{2}$ serum. Hepatocytes were isolated from untreated rats (UT) or rats treated with TA $4 \mathrm{~h}$ before

death (TA). Sodium dodecyl sulfate- $9 \%$ polyacrylamide gels were loaded with $10 \mu \mathrm{g}$ of microsomal proteins (MIC) and $20 \mu \mathrm{g}$ of PM proteins. The nitrocellulose blots were developed with an anti-LKM serum (patient 3 in Table IV) that was used either unchanged or after it had been reacted with $1 \mathrm{mM}$ TA (anti-LKM $2+\mathrm{TA})$. This experiment was repeated five times and the densitometric quantitations are set out in Table III. 
Table III. Densitometric Quantitation of the P450 2C11 Band Recognized by an Anti-LKM Serum in Microsomal and PM Fractions from Untreated and TA-treated Rat Hepatocytes

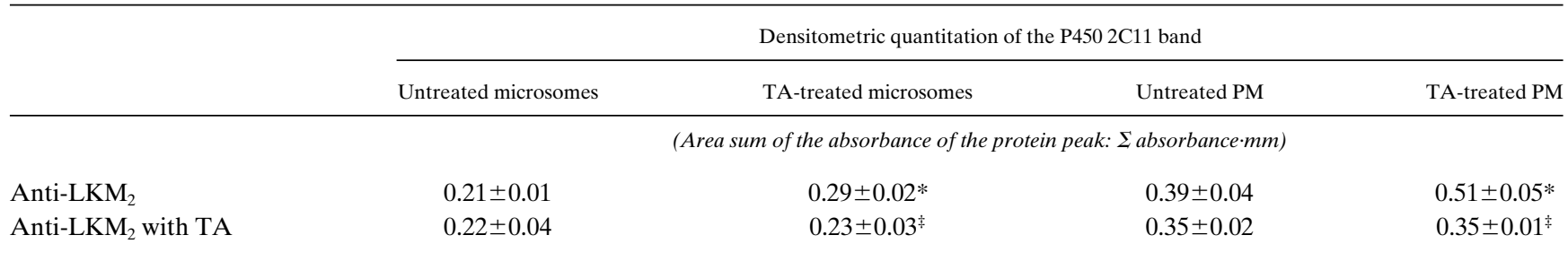

Five successive immunoblots were performed with an anti-LKM 2 serum, as indicated in Fig. 8, and the P450 2C11 band (means \pm SEM) was quantitated by laser scanning. *Significant difference from the same fraction in untreated rats, $P<0.01$ (Student's $t$ test for paired data). ${ }^{\ddagger}$ Significant difference from anti-LKM 2 alone, $P<0.05$ (Student's $t$ test for paired data).

expression of both P450 2C11 and TA-alkylated P450 2C11 on the PM (Table II).

Immunoblotting assessment of the presence of antibodies against P450 2C11-TA metabolite adducts in an anti- $\mathrm{LKM}_{2}$ serum. Anti- $\mathrm{LKM}_{2}$ human sera have been shown to recognize unalkylated P450 2C11 in untreated rat microsomes (7). To determine whether these human sera also contain antibodies against TA metabolite-protein adducts, immunoblots of microsomal and PM proteins were prepared from hepatocytes of either untreated or TA-treated rats, and were revealed with an anti-LKM ${ }_{2}$ serum (Fig. 8, Table III). With proteins from TAtreated rats, the recognition of the $\mathrm{P} 4502 \mathrm{C} 11$ band was significantly higher than with proteins of untreated rats (Table III). Prior reaction of the anti- $\mathrm{LKM}_{2}$ serum with TA (a procedure that should suppress recognition of TA-alkylated proteins) decreased the labeling of TA-treated rat proteins to the lower levels that were observed, without adsorption, in untreated rat proteins (Table III). This provided a preliminary indication of the presence of anti-P450 2C11-TA metabolite adducts among the antibodies that are present in anti-LKM 2 sera.
Flow cytometric demonstration of the recognition of TAalkylated $\mathrm{P} 4502 \mathrm{Cl1}$ by anti-LKM $\mathrm{K}_{2}$ sera. To confirm these results, flow cytometry analysis was then performed with five anti- $\mathrm{LKM}_{2}$ sera (Table IV). We first used unadsorbed sera. Because these sera recognize unalkylated P450 2C11 and this protein is present on the surface of untreated rat hepatocytes, they should recognize the PM of untreated cells. As expected, all five sera gave strong fluorescence on the PM of untreated rat hepatocytes and this recognition was unaffected by the addition of TA $(1 \mathrm{mM})$ to the anti-LKM 2 sera (Table IV). However, this PM labeling was higher with hepatocytes from TA-treated rats (Table IV). With these treated hepatocytes, labeling was decreased when the sera were first reacted with TA prior to their addition to hepatocytes (Table IV), suggesting that anti- $\mathrm{LKM}_{2}$ sera also contain antibodies against TA-alkylated proteins.

To eliminate the anti-P450 2C11 autoantibodies, and selectively study the antibodies recognizing $\mathrm{TA}$, the anti- $\mathrm{LKM}_{2}$ sera were then preadsorbed on untreated rat liver microsomes before being added to the hepatocyte suspensions. These ad-

Table IV. Flow Cytometric Analysis of the Recognition of Rat Hepatocytes by Anti-LKM $M_{2}$ Sera

\begin{tabular}{|c|c|c|c|c|c|c|c|c|}
\hline \multirow[b]{2}{*}{ Patient's serum } & \multirow[b]{2}{*}{ Hepatocytes } & \multicolumn{7}{|c|}{ Specific fluorescence } \\
\hline & & $\begin{array}{l}\text { Unadsorbed } \\
\text { anti-LKM }\end{array}$ & $\begin{array}{c}\text { Unadsorbed } \\
\text { anti-LKM } \\
2\end{array}$ & $\begin{array}{c}\text { adsorbed } \\
\text { anti-LKM } \\
\end{array}$ & $\begin{array}{c}\text { adsorbed anti-LKM } \\
\text { +acetaminophen }\end{array}$ & $\begin{array}{c}\text { Adsorbed } \\
\text { anti- }-\mathrm{LKM}_{2}+\mathrm{TA} \\
\end{array}$ & $\begin{array}{l}\text { Adsorbed anti-LKM } \\
\text { preceded by anti-TA }\end{array}$ & $\begin{array}{c}\text { Adsorbed anti-LKM } \\
\text { preceded by anti-2C11 } \\
\end{array}$ \\
\hline \multicolumn{9}{|c|}{ (Fluorescence Units) } \\
\hline \multirow[t]{2}{*}{1} & UT & $8.5 \pm 1.5$ & $7.3 \pm 1.2$ & $0.4 \pm 0.3 *$ & $0.5 \pm 0.1$ & $1.1 \pm 0.3$ & $1.4 \pm 0.1$ & $1.0 \pm 0.2$ \\
\hline & TA & $13.1 \pm 0.3^{\ddagger}$ & $11.2 \pm 0.6^{*}$ & $4.2 \pm 0.4^{* \neq}$ & $3.3 \pm 0.7$ & $2.2 \pm 0.6^{\S}$ & $1.2 \pm 0.1^{\S}$ & $1.0 \pm 0.2^{\S}$ \\
\hline \multirow[t]{2}{*}{2} & UT & $10.0 \pm 1.3$ & $9.3 \pm 1.8$ & $0.25 \pm 0.04 *$ & $1.1 \pm 1.3$ & $0.2 \pm 0.1$ & $0.4 \pm 0.3$ & $0.5 \pm 0.5$ \\
\hline & TA & $12.5 \pm 0.4^{\ddagger}$ & $11.2 \pm 0.7$ & $2.5 \pm 0.2 * \ddagger$ & $3.0 \pm 0.4$ & $1.5 \pm 0.4^{\S}$ & $1.0 \pm 0.2^{\S}$ & $1.4 \pm 0.5^{\S}$ \\
\hline \multirow[t]{2}{*}{3} & UT & $8.0 \pm 1.1$ & $6.9 \pm 1.1$ & $2.0 \pm 0.5^{*}$ & $3.0 \pm 0.7$ & $1.9 \pm 0.4$ & $1.8 \pm 0.1$ & $2.1 \pm 0.8$ \\
\hline & TA & $11.3 \pm 0.6^{\ddagger}$ & $7.5 \pm 1.0 *$ & $3.2 \pm 0.2 * \ddagger$ & $3.8 \pm 0.4$ & $2.2 \pm 0.2^{\S}$ & $1.1 \pm 0.3^{\S}$ & $1.0 \pm 0.2^{\S}$ \\
\hline \multirow[t]{2}{*}{4} & UT & $10.8 \pm 0.4$ & $11.9 \pm 0.9$ & $0.8 \pm 0.1^{*}$ & $1.3 \pm 1.1$ & $0.7 \pm 0.2$ & $0.9 \pm 0.7$ & $1.0 \pm 0.3$ \\
\hline & TA & $12.4 \pm 0.6$ & $10.5 \pm 0.6^{*}$ & $1.4 \pm 0.1^{* \ddagger}$ & $1.5 \pm 0.2$ & $1.1 \pm 0.2$ & $0.05 \pm 0.02^{\S}$ & $0.8 \pm 0.1^{\S}$ \\
\hline \multirow[t]{2}{*}{5} & UT & $10.1 \pm 0.4$ & $10.8 \pm 2.0$ & $2.1 \pm 0.9^{*}$ & $2.1 \pm 0.7$ & $3.0 \pm 0.1$ & $2.3 \pm 0.8$ & $2.5 \pm 0.4$ \\
\hline & TA & $12.6 \pm 0.5^{\ddagger}$ & $10.5 \pm 0.8 *$ & $2.4 \pm 0.3^{*}$ & $3.3 \pm 0.3$ & $1.0 \pm 0.3^{\S}$ & $1.2 \pm 0.4$ & $0.89 \pm 0.02^{\S}$ \\
\hline
\end{tabular}

Hepatocytes were prepared from untreated rats (UT) or rats treated with TA $4 \mathrm{~h}$ before sacrifice. Hepatocytes were exposed to control sera or anti$\mathrm{LKM}_{2}$ sera. The latter were either unadsorbed or previously adsorbed on untreated rat liver microsomes. Some sera were first reacted with TA or acetaminophen $\left(1 \mathrm{mM}\right.$, each). In other tests, hepatocytes were first exposed to the anti-2C11 or anti-TA antibodies before adding the anti-LKM $\mathrm{L}_{2}$ serum. The linear fluorescence intensity with the control serum was subtracted from that with the anti- $\mathrm{LKM}_{2}$ serum. The difference (specific fluorescence) is set out in the Table. Results are means \pm SEM for three experiments, each in triplicate. *Significant difference from same hepatocyte suspension after exposure to the unadsorbed anti-LKM $(P<0.01)$. ${ }^{*}$ Significant difference from untreated hepatocytes in the same system (unadsorbed or adsorbed anti-LKM 2$)(P<0.05)$. ${ }^{8}$ Significant difference from TA-treated hepatocytes exposed to the adsorbed anti-LKM2 $(P<0.05)$. 
sorbed sera did not recognize (sera 1 and 2) or poorly recognized (sera 3-5) the PM of untreated rat hepatocytes (Table IV). Except for serum 5, these adsorbed sera better recognized the PM of TA-treated hepatocytes (Table IV). This recognition was decreased when the sera were first reacted with TA (whereas acetaminophen had no effect), or when the anti$\mathrm{LKM}_{2}$ sera were preceded by the addition of the anti-TA antibody (Table IV), indicating that the adsorbed sera recognized TA-containing structures. This PM labeling was also markedly decreased by preexposure to the anti-P450 2C11 antibody (Table IV), indicating that TA and P450 2C11 were present on the same structure, i.e., TA-alkylated P450 2C11. In contrast, none of these additional treatments modified the reactivity of the adsorbed anti-LKM $\mathrm{KM}_{2}$ sera towards untreated rat hepatocytes (Table IV).

\section{Discussion}

TA-induced hepatitis is associated with anti-P450 (anti-LKM ${ }_{2}$ autoantibodies $(5,6)$. With other drugs, however, the immune reaction is directed, at least in part, against neoantigens (19-22). The aim of the present study was to determine whether the immune reaction in TA-induced hepatitis would also include antibodies against neoantigens.

The $\mathrm{P} 450$ isoform involved in both the metabolic activation of TA and the recognition of microsomes by anti-LKM $\mathrm{LM}_{2}$ autoantibodies, is P450 2C9 in humans (2-4), but P450 2C11 in rats, a rat isoform that has $85 \%$ sequence identity with $\mathrm{P} 450$ 2C9 (7). Indeed, anti-LKM $\mathrm{LM}_{2}$ sera and anti-P450 2C11 antibodies gave similar immunofluorescence patterns on rat liver and kidney sections (7). Immunoblot testing of anti-LKM $\mathrm{LM}_{2}$ sera with liver microsomes from rats that received various treatments or with purified rat P450s 1A1, 1A2, 2B1, 2B2, 2C6, 2C11, and 4A1 showed that anti-LKM ${ }_{2}$ sera mainly reacted with $\mathrm{P} 450$ $2 \mathrm{C} 11$ (7). Anti-LKM $\mathrm{KM}_{2}$ sera inhibited the metabolic activation of tienilic acid by rat liver microsomes (7). Because of these close analogies, the rat model was selected to study the in vivo formation, transport, and PM expression of TA-derived neoantigens.

We used an antibody raised against TA-albumin adducts (3), and immunoprecipitation and immunoblot experiments to determine which ER protein(s) were alkylated by TA in TA-treated rats. $\mathrm{P} 4502 \mathrm{C} 11$ was the only protein that was immunoprecipated by the anti-TA antibody in microsomes from TAtreated rat hepatocytes (Fig. 3) and the main protein recognized by the anti-TA antibody in immunoblots (Fig. 4). Both immunoblotting (Figs. 4 and 5) and flow cytometry experiments (Table I) showed that TA-alkylated P450 2C11 was present in the plasma membrane of TA-treated male rats. In contrast, the anti-TA antibody poorly recognized the PM in female rats (Fig. 6), which do not express P450 2C11 (26). Thus, P450 2C11 was the main protein that was alkylated by TA in both the ER and PM of TA-treated male rats. Similarly, when P450 2C9-expressing yeast microsomes were incubated with TA and NADPH, P450 2C9 was the main protein that was alkylated (3). These observations suggest that the reactive TA metabolite is so highly unstable that it mainly reacts with the protein that forms it.

There is an extensive flow of vesicles that migrate along microtubules from the ER to the Golgi and then the PM (11). In a previous study, $\mathrm{P} 4502 \mathrm{~B}$ in part followed this vesicular route from the ER to the PM (12). In the present study, we de- termined the in vitro effects of various inhibitors of vesicular transport on the PM expression of both P450 2C11 and TAalkylated P450 2C11 (Table II). The transport of the latter was studied in the presence of piperonyl butoxide. Together with the probable removal of most unbound TA by liver perfusion and the washings involved in the preparation of isolated hepatocytes, the addition of this cytochrome P450 inhibitor should prevent further in vitro alkylation of P450 2C11. Cycloheximide, which may interrupt the synthesis of proteins involved in vesicular transport (12), caffeine at $20^{\circ} \mathrm{C}$, which decreases vesicular flow from the ER to the Golgi apparatus (32), brefeldin A, which redistributes Golgi structures back into the ER (33), and vinblastine or colchicine, which both inhibit the assembly of microtubules and the flow of vesicles along microtubules $(31,34)$, all decreased the expression of both P450 2C11 and TA-alkylated P450 2C11 in the PM (Table II). Colchicine had similar effects in vivo (Table I), showing that the same vesicular transport was operating. Thus, both P450 2C11 and TAalkylated P450 2C11 follow a microtubule-dependent, vesicular route from the ER to the PM.

As $2 \mathrm{~h}$ were enough to decrease the PM expression of both P450 2C11 and TA-alkylated P450 2C11 in these in vitro experiments (Table II), this P450, like P450 2B (12), seems to have a rapid turnover in the PM. This is probably due to the rapid reinternalization of the $\mathrm{PM}$ due to endocytosis. It is estimated that most cells will capture, by endocytosis, the equivalent of their volume per day and internalize the equivalent of their PM per hour (35).

In contrast, the PM expression of TA-alkylated P450 2C11 exhibited a much more prolonged time course after TA administration in vivo (Fig. 7). This may be due to the persistence of TA in the liver (and the prolonged activation of TA by $\mathrm{P} 450$ 2C11, in vivo) and/or to the possible recycling of endocytosed P450 back to the PM.

PM fractions of hepatocytes exhibit NADPH-cytochrome $c$ reductase activity, and these PM fractions can support monooxygenase activities in the presence of NADPH in vitro (13). Therefore, the PM expression of TA-alkylated P450 2C11 in TA-treated rats in vivo may result from two pathways: $(a)$ the migration of unalkylated P450 2C11 to the PM and then its alkylation by TA in the PM; or (b) the alkylation of P450 2C11 in the ER and its migration to the PM. Administration of TA (to allow the formation of TA-alkylated P450 2C11) and then piperonyl butoxide $1 \mathrm{~h}$ before killing (to stop any new formation of adducts, while allowing the turnover of P450s in the PM) should discriminate between these two alternatives. If metabolic activation occurs last, piperonyl butoxide should decrease TA-alkylated P450 in the PM; if transport occurs last, piperonyl butoxide should have no effect. The results (Fig. 5, Table I) support the latter alternative (alkylation in the ER and migration of alkylated P450 2C11 to the PM). Similarly, after administration of isaxonine, a drug transformed by several $\mathrm{P} 450$ s into reactive metabolites that produce immunoallergic hepatitis, the PM expression of alkylated proteins was due to proteins that had been alkylated in the ER and had migrated to the PM (36). Although PM P450s are catalytically active in PM fractions incubated with NADPH (13), they may be inactive in vivo, if they are mainly located on the external side of the PM, where NADPH may be unavailable.

The use of nonpermeabilized hepatocytes in flow cytometry experiments prevents the entry of the antibodies into the cells. Therefore, recognition of the PM by both the anti-P450 
2C11 and the anti-TA antibody shows that at least some of the P450 2C11 molecules are outside the PM. Similarly, other P450s were, at least in part, oriented on the outside of the PM (12-14). This was demonstrated by: $(a)$ the labeling of fixed hepatocytes (12-14), as performed in the present study; $(b)$ the observation of a capping phenomenon when anti-P450 antibodies were added to unfixed hepatocytes (14); and (c) the PM labeling of hepatocytes when human liver fragments were perfused with anti-LKM $\mathrm{M}_{1}$ sera before liver sections were prepared for electron microscopy (14). Thus, PM P450s are, at least in part, oriented on the external surface of the PM (12-14).

How this occurs remains unknown. P450s are cotranslationnally inserted into the ER membrane, where they remain anchored by a non-cleaved signal-anchor sequence, which, for most P450s, starts immediately at the $\mathrm{N}$-terminal methionine (8). It is believed that ER P450s are exclusively (or mainly?) oriented as follows. No part of the molecule (except the N-terminal methionine) protrudes into the ER lumen (9). Except for the transmembrane segment, the molecule is located on the cytosolic side of the ER membrane (9). Vesicular migration of this cytosolic form to the PM should lead to a cytosolically oriented form in the PM (unless P450 switches to the opposite topology during its transport from the ER to the PM, which seems unlikely) (12).

We have therefore suggested that P450s may adopt two topologies during their synthesis in the ER (12). Dual topologies have been described for other ER proteins $(37,38)$. The known, cytosolically oriented form of P450 would be retained and predominant in the ER (12), due to the cytosolic domain serving as an ER retention signal (10). We have suggested that a hypothetical luminal form of $\mathrm{P} 450$ may also be formed during P450 synthesis in the ER (12) and this hypothesis is supported by ongoing experiments in our laboratory. This luminal form of P450 would not be retained in the ER (the retention signal would be in the lumen), and would therefore quickly follow, by default, bulk vesicular flow to the PM, to finish on the external surface of this membrane (12). Due to its rapid migration to the PM, this endoluminal form would only be a minor form in the ER, explaining why it was not noticed in previous studies.

Because human P450 2C9 is also alkylated by TA (2-4), and unalkylated P450 2C9 is also expressed on the PM of human hepatocytes (14), human subjects who were treated with TA probably expressed TA-alkylated P450 2C9 on the outer surface of their hepatocytes. We therefore determined whether the immune reaction was also directed against these neoantigens in patients with TA-induced hepatitis. Both immunoblots and flow cytometry indicated that anti-LKM 2 sera contained two types of antibodies (Tables III and IV). A first and major type of antibodies recognized the unalkylated P450 2C11 of the PM of untreated rats (Tables III and IV). However, anti$\mathrm{LKM}_{2}$ sera gave slightly higher labelings with hepatocytes from TA-treated rats (Tables III and IV), suggesting that they may also contain anti-TA antibodies. After adsorption of the anti-P450 autoantibodies on untreated rat liver microsomes, this second type of antibodies could be selectively studied (Table IV). The residual antibodies poorly recognized the PM of untreated rats, but better recognized the PM of TA-treated rats (Table IV). This PM labeling was decreased when sera were first reacted with TA, or following the addition of the anti-TA antibody, showing that the sera recognized TA-containing structures (Table IV). Because P450 2C11 is the main protein that is alkylated by TA (Figs 3 and 4), these observations suggested that the antibodies recognized TA-alkylated P450 2C11. Indeed, the PM labeling was also decreased following preexposure to the anti-P450 2C11 antibody (Table IV), suggesting that TA and P450 2C11 were present on the same structure, i.e., TA-alkylated P450 2C11. Taken together, these observations indicated that this second type of antibodies recognized the TA moiety of TA-alkylated P450.

Thus, the immune reaction in TA-induced hepatitis is directed both against unalkylated P450 (anti-P450 2C autoantibodies) and against TA-alkylated P450. Similarly, both autoantibodies $(39,40)$ and antibodies against trifluoracetylated proteins $(19,20)$ have been detected in halothane hepatitis. Thus, with both drugs, the immune reaction is directed both against the Self and against the modified Self. The same initial mechanism (modification of Self due to the covalent binding of reactive metabolites) has been suggested to account for both types of immune reactions (18). Therefore, their concomitant occurrence is not unexpected. Both genetic metabolic factors and the individual set of human leukocyte antigen molecules might be involved in the susceptibility of a few subjects to develop drug-induced immune reactions (18).

In summary, TA administration leads to the selective alkylation of hepatic P450 2C11 in rats. This alkylated P450 follows a vesicular route from the ER to the PM. It is at least in part oriented on the external surface of the PM. In addition to the previously demonstrated anti-P450 2C9/11 autoantibodies, anti-LKM $\mathrm{L}_{2}$ sera also contain antibodies against the TA moiety of TA-alkylated P450. Therefore, the immune reaction is directed both against the Self and against neoantigens.

\section{Acknowledgments}

We thank Philippe Valadon (URA 400 CNRS) for the gift of the antiTA antibody and Professor J.C. Homberg (Laboratoire d'Immunologie, Hôpital Saint-Antoine, Paris, France) for providing the anti$\mathrm{LKM}_{2}$ sera.

This work was supported in part by the CEE (Biotech) grant B102 CT 92-0316, the European Union BIOMED 2 grant PL 950658, and by the BIO AVENIR INSERM/Rhone Poulenc Rorer contract 95133.

\section{References}

1. Zimmerman, H.J., J.H. Lewis, K.G. Ishak, and W.C. Maddrey. 1984. Ticrynafen-associated hepatic injury: analysis of 340 cases. Hepatology. 4:315-323.

2. Lopez Garcia, M.P., P.M. Dansette, P. Valadon, C. Amar, P.H. Beaune, F.P. Guengerich, and D. Mansuy. 1993. Human-liver cytochromes P-450 expressed in yeast as tools for reactive-metabolite formation studies. Oxidative activation of tienilic acid by cytochromes P-450 2C9 and 2C10. Eur. J. Biochem. 213:223-232.

3. Lecoeur, S., E. Bonierbale, D. Challin, J.C. Gautier, P. Valadon, P.M. Dansette, R. Catinot, F. Ballet, D. Mansuy, and P.H. Beaune. 1994. Specificity of in vitro covalent binding of tienilic acid metabolites to human liver microsomes in relationship with the type of hepatotoxicity: Comparison with two directly hepatotoxic drugs. Chem. Res. Toxicol. 7:434-442.

4. Lopez Garcia, M.P., P. Dansette, and D. Mansuy. 1994. Thiophene derivatives as new mechanism-based inhibitors of cytochrome P450: inactivation of yeast-expressed human liver P450 2 C9 by tienilic acid. Biochemistry. 33:166175 .

5. Homberg, J.C., C. André, and N. Abuaf. 1984. A new anti-liver-kidney microsome antibody $\left(\right.$ anti-LKM $\left.\mathrm{LM}_{2}\right)$ in tienilic acid induced hepatitis. Clin. Exp. Immunol. 55:561-570.

6. Beaune, P., P.M. Dansette, D. Mansuy, L. Kiffel, M. Finck, C. Amar, J.P. Leroux, and J.C. Homberg. 1987. Human anti-endoplasmic reticulum autoantibodies appearing in a drug-induced hepatitis are directed against a human liver cytochrome P-450 that hydroxylates the drug. Proc. Natl. Acad. Sci. USA 84: 551-555.

7. Pons, C., P.M. Dansette, C. Amar, M. Jaouen, R. Wolf, J. Gregeois, J.C. 
Homberg, and D. Mansuy. 1991. Detection of human hepatitis anti-liver kidney microsomes (LKM2) autoantibodies on rat liver sections is predominantly due to reactivity with rat liver P-450 IIC11. J. Pharmacol. Exp. Ther. 259:1328-1334.

8. Yamazaki, S., K. Sato, K. Suhara, M. Sakaguchi, K. Mihara, and T. Omura. 1993. Importance of the proline-rich region following signal-anchor sequence in the formation of correct conformation of microsomal cytochrome P-450s. J. Biochem. 114:652-657.

9. Black, S.D., S.T. Martin, and C.A. Smith. 1994. Membrane topology of liver microsomal cytochrome P450 2B4 determined via monoclonal antibodies directed to the halt transfer signal. Biochemistry. 33:6945-6951.

10. Szczesna-Skorupa, E., K. Ahn, C.D. Chen, B. Doray, and B. Kemper. 1995. The cytoplasmic and N-terminal transmembrane domains of cytochrome $\mathrm{P} 450$ contain independent signals for retention in the endoplasmic reticulum. $J$. Biol. Chem. 41:24327-24332.

11. Myrset, A.H., B. Halvorsen, E. Ording, and L. Helgeland. 1993. The time course of intracellular transport of some secretory proteins of rat liver are not affected by an induced acute phase response. Eur. J. Cell Biol. 60:108-114.

12. Robin, M.A., M. Maratrat, J. Loeper, A.M. Durand-Schneider, M. Tinel, F. Ballet, P.H. Beaune, G. Feldmann, and D. Pessayre. 1995. Cytochrome $\mathrm{P} 4502 \mathrm{~B}$ follows a vesicular route to the plasma membrane in cultured rat hepatocytes. Gastroenterology. 108:1110-1123.

13. Loeper, J., V. Descatoire, M. Maurice, P. Beaune, G. Feldmann, D. Larrey, and D. Pessayre. 1990. Presence of functional cytochrome P-450 on isolated rat hepatocyte plasma membrane. Hepatology. 11:850-858.

14. Loeper, J., V. Descatoire, M. Maurice, P. Beaune, J. Belghiti, D. Houssin, F. Ballet, G. Feldmann, F.P. Guengerich, and D. Pessayre. 1993. Cytochrome P-450 on human hepatocyte plasma membrane. Recognition by several autoantibodies. Gastroenterology. 104:203-216.

15. Beaune, P., D. Pessayre, P.M. Dansette, D. Mansuy, and M. Manns. 1994. Autoantibodies against cytochromes P450: Role in human diseases. Adv. Pharmacol. 30:199-245.

16. Bourdi, M., M. Tinel, P. Beaune, and D. Pessayre. 1994. Interactions of dihydralazine with cytochromes P4501A: A possible explanation for the appearance of anti-P4501A2 autoantibodies. Mol. Pharmacol. 45:1287-1295.

17. Bourdi, M., D. Larrey, J. Nataf, J. Bernuau, D. Pessayre, M. Iwasaki, F.P. Guengerich, and P.H. Beaune. 1990. Anti-liver endoplasmic reticulum autoantibodies are directed against human liver cytochrome P-450 IA2. A specific marker of dihydralazine-induced hepatitis. J. Clin. Invest. 85:1967-1973.

18. Pessayre, D. 1995. Role of reactive metabolites in drug-induced hepatitis. J. Hepatol. 23(Suppl. 1):16-24.

19. Kenna, J.G., H. Satoh, D.D. Christ, and L.R. Pohl. 1988. Metabolic basis for a drug hypersensitivity: antibodies in sera from patients with halothane hepatitis recognize liver neoantigens that contain the trifluoroacetyl group derived from halothane. J. Pharmacol. Exp. Ther. 245:1103-1109.

20. Satoh, H., Y. Fukuda, D.K. Anderson, V.J. Ferrans, J.R. Gillette, and L.R. Pohl. 1985. Immunological studies on the mechanisms of halothaneinduced hepatotoxicity: immunohistochemical evidence of trifluoroacetylated hepatocytes. J. Pharmacol. Exp. Ther. 223:857-862.

21. Neuberger, J., J.G. Kenna, K.N. Aria, and R. Williams. 1985. Antibody mediated hepatocyte injury in methyl-dopa induced hepatotoxicity. Gut. 26: 1233-1239.

22. Spiroudhis, L., M. Beaugrand, Y. Malledant, P. Brissot, C. GuguenGuillouzo, and A. Guillouzo. 1991. Use of adult human hepatocytes in primary culture for the study of clometacin-induced immunoallergic hepatitis. Toxicol. In Vitro. 5:529-534.

23. Neuberger, J., and R. Williams. 1989. Immune mechanisms in tienilic acid asociated hepatotoxicity. Gut. 30:515-519.

24. Guide for the care and use of laboratory animals (NIH publication 8623). 1985. Bethesda, MD: National Institutes of Health.

25. Tinel, M., M.A. Robin, J. Doostzadeh, M. Maratrat, F. Ballet, N. Fardel, J. El Kahwaji, P. Beaune, M. Daujat, G. Labbe, and D. Pessayre. 1995. The interleukin-2 receptor down-regulates the expression of cytochrome P450 in cultured rat hepatocytes. Gastroenterology. 109:1589-1599.

26. Guengerich, F.P., G.A. Dannan, S.T. Wright, M.V. Martin, and L.S. Kaminsky. 1982. Purification and characterization of liver microsomal cytochromes P-450: electrophoretic, spectral, catalytic and immunochemical properties and inducibility of eight isozymes isolated from rats treated with phenobarbital or $\beta$-naphthoflavone. Biochemistry. 21:6019-6030.

27. Volz, B., G. Orberger, S. Porwoll, H.P. Hauri, and R. Tauber. 1995. Selective reentry of recycling cell surface glycoproteins to the biosynthetic pathway in human hepatocarcinoma HepG2 cells. J. Cell Biol. 130:537-551.

28. Dormard, Y., J.C. Levron, P. Adnot, T. Lebedeff, and G. Enjoubault. 1976. Pharmacokinetic study of 2,3-dichloro 4-[2-thienyl keto $\left.{ }^{14} \mathrm{C}\right]$ phenoxyacetic acid (Tienilic acid) in animals. I. Localisation, distribution and elimination of ${ }^{14} \mathrm{C}$ tienilic acid in animals. Eur. J. Drug Metab. Pharmacokinet. 1:41-49.

29. Mansuy, D. 1981. Use of model sytems in biochemical toxicology: heme models. In Reviews in Biochemical Toxicology. E. Hogson, J.R. Bend, R.M Philpoy, editors. Elsevier Science Publishing Co. Inc., New York. 283-320.

30. Sinclair, J.F., P.R. Sinclair, J.F. Healey, E.L. Smith, and H.L. Bonkowsky. 1982. Decrease in hepatic cytochrome P-450 by cobalt. Evidence for a role of cobalt protoporphyrin. Biochem. J. 204:103-109.

31. Hastie, S.B. 1991. Interactions of colchicine with tubulin. Pharmacol. Ther. 51:377-401.

32. Jäntti, J., and E. Kuismanen. 1993. Effect of caffeine and reduced temperature $\left(20^{\circ} \mathrm{C}\right)$ on the organization of the pre-Golgi and the Golgi stack membranes. J. Cell Biol. 120:1321-1335.

33. Miller, S.G., L. Carnell, and H.P.H. Moore. 1992. Post-Golgi membrane traffic: brefeldin A inhibits export from distal Golgi compartments to the cell surface but not recycling. J. Cell Biol. 118:267-283.

34. Hamel, E. 1992. Natural products which interact with tubulin in the vinca domain: maytansine, rhizoxin, phomopsin A, dolastatins 10 and 15 and halichondrin B. Pharmacol. Ther. 55:31-51.

35. Cupers, P., A. Veithen, and P.J. Courtoy. 1995. La clathrine est-elle superflue pour l'endocytose non spécifique? Med. Sci. 11:1271-1278.

36. Loeper, J., V. Descatoire, G. Amouyal, P. Lettéron, D. Larrey, and D. Pessayre. 1989. Presence of covalently bound metabolites on rat hepatocyte plasma membrane proteins after administration of isaxonine, a drug leading to immunoallergic hepatitis in man. Hepatology. 9:675-678.

37. Sakata, N., X. Wu, J.L. Dixon, and H.N. Ginsberg. 1993. Proteolysis and lipid-facilitated translocation are distinct but competitive processes that regulate secretion of apolipoprotein B in HepG2 cells. J. Biol. Chem. 268:22967-22970.

38. Alves, C., P. von Dippe, M. Amoui, and D. Levy. 1993. Bile acid transport into hepatocyte smooth endoplasmic reticulum vesicles is mediated by microsomal epoxide hydrolase, a membrane protein exhibiting two distinct topological orientations. J. Biol. Chem. 268:20148-20155.

39. Martin, J.L., G.F. Reed, and L.R. Pohl. 1993. Association of anti-58kDa endoplasmic reticulum antibodies with halothane hepatitis. Biochem. Pharmacol. 46:1247-1250.

40. Pumford, N.R., B.M. Martin, D. Thomassen, J.A. Burris, J.G. Kenna, J.L. Martin, and L.R. Pohl. 1993. Serum antibodies from halothane hepatitis patients react with the rat endoplasmic reticulum protein ERp72. Chem. Res. Toxicol. 6:609-615. 